\title{
Junk Food Addiction Across Generations in Urban Karnataka, India
}

\author{
NR Ramesh Masthi', Afraz Jahan ${ }^{2}$ \\ ${ }^{1}$ Professor and HOD, ${ }^{2}$ Tutor cum Post Graduate, Department of Community Medicine, Kempegowda Institute of Medical \\ Sciences, Banashankari II Stage, Bengaluru, Karnataka, India.
}

DOI: https://doi.org/10.24321/0019.5138.202008

\section{I $\quad \mathbf{N} \quad \mathbf{F} \quad \mathbf{O}$}

\section{Corresponding Author:}

Afraz Jahan, Department of Community Medicine, Kempegowda Institute of Medical Sciences, Banashankari II Stage, Bengaluru, Karnataka, India.

E-mail Id:

dr.afrazjahan@gmail.com

Orcid Id:

https://orcid.org/0000-0002-3523-6860

How to cite this article:

Masthi NRR, Jahan A. Junk Food Addiction Across Generations in Urban Karnataka, India. J Commun Dis 2020; 52(1): 65-71.

Date of Submission: 2020-01-16

Date of Acceptance: 2020-04-01

\section{$\begin{array}{llllllll}\mathbf{A} & \mathbf{B} & \mathbf{S} & \mathbf{T} & \mathbf{R} & \mathbf{A} & \mathbf{C} & \mathbf{T}\end{array}$}

Background: Junk food consumption is progressing from being just an unhealthy life style habit to a full-fledged addiction.

Objectives: To assess the health problems related to junk food habits; To assess the burden of addiction to junk food using a novel junk food addiction scale and to describe the alternate diets followed.

Methodology: A cross-sectional study was conducted among people across three generations: Generation X, Millenials and Generation Z residing in urban Karnataka, India. Using convenient sampling, a sample size of 500 subjects were selected. Addiction to junk food was assessed by a novel Junk Food Addiction Scale developed for the study.

Result: All 500 study subjects had consumed either junk/street/fast/ instant food any time in the past 1 year. A total of 211 (42.2\%) subjects reported acute health problem and $182(36.4 \%)$ chronic health problems following junk food consumption. The burden of junk food addiction was found to be 80 (16\%) [Cl (95\%): 13.32-18.68] of which majority 70 (14\%) had mild addiction. The prevalence of different fad diets followed for 3 months or more was 137 (27.4\%).

Conclusion: Junk food addiction was observed in more than one tenth of the subjects. Majority had mild addiction and observed equally between Millennials and Generation Z. Obesity, habits and gadgets had independent effects on junk food addiction. More than one forth subjects followed fad diets.

Keywords: Junk Food, Food Addiction, Health Effects, Exploratory Study

\section{Introduction}

India is a country of paradox where you can see plenty and nothing at the same time. Nutrition is a classic example where under-nutrition, a major public health problem in the past is now giving way to obesity as an emerging health problem. Both are seen simultaneously because of the rapid urbanization.
Various shifts in food habits have been seen among millennials ranging from consumption of apparently healthy food to mindless eating of junk food, following economic growth in the country. In India, more and more people having junk food is a trend observed not only in the younger generation but also across all age groups replacing a balanced diet. The terms fast food and junk 
food are often used interchangeably. Most of the junk foods are fast foods as they are prepared and served fast, but not all fast foods are junk foods, especially when they are prepared with nutritious contents. ${ }^{1,2}$ Junk food consumption is progressing from being just an unhealthy life style habit to a full-fledged addiction. High-calorie junk food is now available as a cheaper and faster alternative to healthy snacks. Fast food chains are cropping up at a fast rate in every corner including smaller towns and cities. The arrival of mobile based apps likes zomato and swiggy in India has made life of foodies easier as food is delivered to doorstep.

Of late, another obsession is consumption of food based on calorie count. Popularity of diets such as Atkins Diet (low carbohydrate diet), Keto diet (low carbohydrate \& high fat), Zone diet (40\% carbohydrates, 30\% fats and 30\% protein) and veganism (excludes the use of animals for food) are a rage among health fanatics. ${ }^{3,4}$ Celebrities following such diets influence people in a major way which further increases the popularity of such diets. Extreme forms of diet followed over a long period of time may lead to the deficiency of important nutrients. These deficiencies are in turn consumed as supplements such as multivitamins, protein powders, energy drinks or steroids. Another food fad gaining popularity are meal replacements such as Herbalife, Nutrilite, to achieve the ideal weight/ body goals. ${ }^{5}$

Junk food addiction, alternate diets and meal replacements are not advisable for healthy living. These extremes in eating habits can have a negative impact on health leading to problems like obesity, diabetes, hypertension, malnutrition, etc. ${ }^{6}$ There are very few studies available on junk food addiction. In this regard, an attempt was made to explore the possibility of addiction to junk food through the use of a novel junk food addiction scale developed with the following objectives: To describe the socio demographic characteristics of the study subjects; to assess the health problems related to junk food habits in the subjects; to assess the burden of addiction to junk food using a novel junk food addiction scale and to explore the alternate diets followed by the subjects.

\section{Materials and Methods}

A cross-sectional study was conducted among people across three generations- Generation X, Millennials and Generation $Z$ residing in selected urban areas of Karnataka State in India during the first quarter of 2019. The sample size was calculated based on the pilot study prevalence of $47 \%$. Taking confidence level to be $95 \%$ and precision error of $10 \%$, the sample size was 451 and was rounded off to 500 .

The data was collected online using Google forms and was made available for a 3-month period from January-March, 2019. The questionnaire was semi-structured with both open and closed-ended questions, and captured details of individual, dietary habits, health problems and addiction to junk food. Addiction to junk food was assessed by a novel Junk Food Addiction Scale which was developed, field tested and validated. Cronbach's alpha showed the questionnaire to reach acceptable reliability, $\alpha=0.91$. The scale had a total of 16 questions, each question was given a score ranging from 0 to 4 (0- Never, 1- Rarely, 2- Occasionally, 3- Often, 4- Always).The score ranged from 0 - 64. The overall scores were graded as normal (0-32), mild (33-48), moderate (4958 ) and severe addiction (>58).

Subjects aged between 18 to 50 years who had an email address and access to Internet were included in the study. Immuno-compromised, chronically ill and the subjects medically advised to follow a particular diet were excluded from the study.

Operational Definitions: Generation X (Gen X) is the demographic cohort born between 1965 to 1980 , Millennials between 1981 to 1996 and Generation Z (Gen Z) from 1997 to present. ${ }^{7}$ Junk Food: Food that contains little or no proteins, vitamins or minerals but is rich in salt, sugar, fats and high in energy (calories). Any food, processed or unprocessed, street or fast, can be termed 'junk' if it has the above features. ${ }^{8}$ Home-cooked food fulfilling the above criteria was also considered as junk food. Nutraceuticals are purported to provide extra health benefits, in addition to basic nutritional value found in foods. ${ }^{8}$ Novel food does not have a significant history of consumption or is produced by a method that has not previously been used for food. ${ }^{8}$ Meal replacements (Nutrilite and Herbalife) are beverages or foods that can be consumed in place of or as part of a meal. ${ }^{9}$

Statistical Analysis: The data was analysed in R Studio and $\mathrm{R}$ Commander Statistical Package. ${ }^{10}$ Descriptive statistics like mean and percentage were calculated. To measure the association between food addiction and background variables, univariate and binominal logistic regression was done. Crude odds ratio, adjusted odds ratio and confidence interval were computed. Spearman's Rank correlation test was applied to compare the relation between Body Mass Index (BMI), addiction score and age. Kruskal-Wallis Rank Sum Test was used to compare median addiction scores between the BMI categories. Z test was used for comparison of proportions. Ethical clearance was obtained from the institutional ethical committee. Informed consent of the subjects was obtained online. They were briefed about the study and only if they volunteered they were asked to participate in the study and confidentiality of subjects was maintained.

\section{Result}

Out of a total of 500 study subjects, 212 (42.4\%) were males and 288 (57.6\%) were females. The median age of the subjects with interquartile range was $22(21,25.25)$ 
years and age range was between 18 to 50 years. Majority of the subjects [345 (69\%)] belonged to the age group of 21 to 30 years. Of the 500 study subjects, 265 (53.0\%) belonged to Generation Z, 220 (44\%) belonged to the millennial generation and 15 (3.0\%) belonged to Generation Y. Two hundred and eighty two (56.4\%) subjects were students, $110(22.0 \%)$ were Health care professionals, 42 (8.4\%) were Engineers, 14 (2.8\%) were Businessmen, 41 (8.2\%) were in various others professions (e.g., lawyer, self-employed, agriculture, etc.) and 11 (2.2\%) were unemployed.

Majority [327(65.4\%)] subjects were non-vegetarians and 78 (15.6\%) subjects were vegetarians. The other diets followed were 41 (8.2\%). Lacto-ovo vegetarianism (vegetarian food with dairy and egg products), 32 (6.4\%) pollotarianism (vegetarian food and poultry meat), 19 (3.8\%) flexitarianism (vegetarian food with occasional exceptions) and 3 (0.6\%) pescetarianism (vegetarian food, fish or invertebrate seafoods). ${ }^{8}$ Of the 303 study subjects residing at home, 291 (96\%) consume home-cooked meals daily, 191 (65.6\%) consume three times a day and $146(48.2 \%)$ had at least one meal with the family. Of the 197 study subjects residing in a hostel/paying guest, $162(82.2 \%)$ ate/ordered food from outside every day.
All 500 study subjects had consumed either junk/street/ fast/ instant food any time in the past 1 year, majority [333 (66.6\%)] subjects consumed it on a daily basis and junk food [179 (35.8\%)] was the most common type of food consumed on daily basis compared to others in both the genders. Among junk food, chocolate/ sweet [96 (53.6\%)] was most commonly consumed daily. The main reasons for consumption of junk food were: 283 (56.6\%) subjects mentioned family/ social gatherings, 275 (55.0\%) cravings, $158(31.6 \%)$ mess/ hostel food not palatable and 126 (25.2\%) subjects said peer pressure. 281 (56.2\%) subjects felt happy, $210(42.0 \%)$ subjects felt guilty, $9(1.8 \%)$ felt nothing at all after consumption of junk food. About 168 (33.6\%) study subjects always check food labels before purchase or consumption, 87 (17.4\%) subjects mentioned checking food labels affects their choices of food. One hundred and seventy eight (35.6\%) subjects monitored their physical activity and $86(17.2 \%)$ subjects monitor their diet using gadgets like smart phone/smart watch/fitbit, etc.

\section{Health Issues Attributed to Junk Food Consumption}

According to the Asia Pacific Guidelines for obesity, ${ }^{11}$ $138(27.6 \%)$ of the subjects fall under the obese class I and 44 (8.8\%) fall under obese Class II, as shown in Table 1.

Table I.Classification of Obesity According to Asia Pacific Guidelines in the Subjects $(n=500)$

\begin{tabular}{|c|c|c|c|c|}
\hline BMI & Female & Male & Total & Z test, $\mathbf{p}$-value \\
\hline Underweight & $24(8.3)$ & $10(4.7)$ & $34(6.8)$ & $1.6,0.1$ \\
\hline Normal & $118(41.0)$ & $64(30.1)$ & $182(36.4)$ & $2.5,0.01$ \\
\hline Overweight: At risk & $51(17.7)$ & $51(24.1)$ & $102(20.4)$ & $1.7,0.08$ \\
\hline Overweight: Obese class I & $81(28.1)$ & $57(26.9)$ & $138(27.6)$ & $0.3,0.76$ \\
\hline Overweight: Obese class II & $14(4.9)$ & $30(14.2)$ & $44(8.8)$ & $3.6,0.0003$ \\
\hline Grand Total & $288(100.0)$ & $212(100.0)$ & $500(100.0)$ & \\
\hline
\end{tabular}

Figures in parenthesis indicate percentages.

Table 2.Association between Junk Food Addiction and Other Variables by Univariate Logistic Regression $(n=500)$

\begin{tabular}{|c|c|c|c|c|c|}
\hline \multicolumn{2}{|c|}{ Variables } & \multirow{2}{*}{$\begin{array}{c}\text { Present }(\mathbf{n}=80) \\
14(17.5)\end{array}$} & \multirow{2}{*}{$\begin{array}{c}\text { Absent }(\mathbf{n}=\mathbf{4 2 0}) \\
98(23.3)\end{array}$} & \multirow{2}{*}{$\begin{array}{c}\text { OR } \\
- \\
\end{array}$} & \multirow{2}{*}{$\begin{array}{c}\text { Univariate p-value } \\
-\end{array}$} \\
\hline \multirow{4}{*}{ Age } & $<20$ & & & & \\
\hline & $21-30$ & $63(78.8)$ & $282(67.2)$ & 1.56 & 0.16 \\
\hline & $31-40$ & $3(3.7)$ & $26(6.2)$ & 0.808 & 0.75 \\
\hline & $41-50$ & - & $14(3.3)$ & $=$ & $=$ \\
\hline \multirow{3}{*}{ Generation } & Gen X & - & $15(3.6)$ & - & - \\
\hline & Millennials & $35(43.8)$ & $185(44.0)$ & 2.96 & 0.98 \\
\hline & Gen Z & $45(56.2)$ & $220(52.4)$ & 3.2 & 0.98 \\
\hline \multirow{2}{*}{ Gender } & Female & $46(57.5)$ & $242(57.6)$ & 0.19 & \\
\hline & Male & $34(42.5)$ & $178(42.4)$ & 1.00 & 0.98 \\
\hline \multirow{3}{*}{ Occupation } & Student & $45(56.2)$ & $237(56.4)$ & - & - \\
\hline & Doctor & $17(21.2)$ & $93(22.1)$ & 0.96 & 0.9 \\
\hline & Engineering & $07(8.8)$ & $35(8.3)$ & 1.05 & 0.9 \\
\hline
\end{tabular}




\begin{tabular}{|c|c|c|c|c|c|}
\hline & Business & $06(7.5)$ & $08(1.9)$ & 3.95 & 0.001 \\
\hline & Others & $05(6.3)$ & $36(8.6)$ & 0.73 & 0.53 \\
\hline & Unemployed & - & $11(2.7)$ & $=$ & $=$ \\
\hline \multirow{4}{*}{ Religion } & Hindu & $67(83.8)$ & 342 (81.4) & - & - \\
\hline & Muslim & $10(12.5)$ & $37(8.8)$ & 1.38 & 0.39 \\
\hline & Christian & $02(2.5)$ & $27(6.4)$ & 0.378 & 0.19 \\
\hline & Others & $01(1.2)$ & $14(3.4)$ & 0.365 & 0.33 \\
\hline \multirow{2}{*}{ Obesity } & Absent & $22(27.5)$ & $194(46.2)$ & - & - \\
\hline & Present & $58(72.5)$ & $226(53.8)$ & 2.26 & 0.002 \\
\hline \multirow{6}{*}{ Diet } & Flexitarianism & $03(3.8)$ & $16(3.8)$ & - & - \\
\hline & Lacto Ovo Veg & $08(10.0)$ & $33(7.9)$ & 1.29 & 0.72 \\
\hline & Non Vegetarian & $60(75.0)$ & 267 (63.6) & 1.2 & 0.77 \\
\hline & Pescetarianism & - & $03(0.7)$ & - & - \\
\hline & Pollotarianism & $05(6.2)$ & $27(6.4)$ & 0.98 & 0.98 \\
\hline & Vegetarian & $04(5.0)$ & $74(17.6)$ & 0.28 & 0.12 \\
\hline \multirow{2}{*}{ Physical activity } & Present & $72(90.0)$ & 365 (86.9) & 1.36 & 0.446 \\
\hline & Absent & $8(10.0)$ & $55(13.1)$ & - & - \\
\hline \multirow{2}{*}{ Habits } & Present & $36(45.0)$ & $101(24.0)$ & 2.580 & 0.0001 \\
\hline & Absent & $44(55.0)$ & $319(76.0)$ & - & - \\
\hline \multirow{3}{*}{$\begin{array}{l}\text { Smartphone/ laptop/ } \\
\text { TV for recreational } \\
\text { purposes }\end{array}$} & $<2$ hours & $13(16.2)$ & $136(32.4)$ & - & - \\
\hline & 2-4 hours & $32(40.0)$ & $177(42.1)$ & 1.89 & 0.06 \\
\hline & $>4$ hours & $35(43.8)$ & $107(25.5)$ & 3.42 & $<0.001$ \\
\hline \multirow{2}{*}{$\begin{array}{l}\text { Use of App/ Fitbit to } \\
\text { monitor diet }\end{array}$} & No & $57(71.3)$ & $357(85.0)$ & & \\
\hline & Yes & $23(28.7)$ & $63(15.0)$ & 2.29 & 0.003 \\
\hline \multirow{2}{*}{$\begin{array}{l}\text { Use of App/ Fitbit to } \\
\text { monitor physical } \\
\text { activity }\end{array}$} & No & $42(52.5)$ & $280(66.7)$ & - & - \\
\hline & Yes & $38(47.5)$ & $140(33.3)$ & 1.81 & 0.01 \\
\hline
\end{tabular}

Figures in parenthesis indicate percentages.

A total of 211 (42.2\%) subjects had attributed one or another acute health problem such as acute gastroenteritis, food poisoning, diarrhoea, vomiting, hepatitis A, typhoid, etc., due to junk food consumption. Diarrhoea [116 (23.2\%)] was the most common acute health problem reported. About 182(36.4\%) subjects attributed chronic health problems such as overweight/obesity, haemorrhoids, hypertension, diabetes observed in them to junk food consumption of which overweight/ obesity was most common.

The overall burden of junk food addiction was found to be 80 (16\%) [95\% Cl: 13.32-18.68] with majority [70 (14\%)] having mild addiction, 7 (1.4\%) moderate addiction and only $3(0.6 \%)$ severe addiction. It was equally observed among Millennials and Generation Z, while no addiction was observed among Generation X. Table 2. describes the association between junk food addiction and the different variables by Univariate Logistic Regression. It was observed that obesity, habits such as drinking/smoking, use of
smartphone/laptop/TV for recreational purposes and use of gadgets for monitoring diet and physical activity were found to be significant.

Finally, to assess overall effect of junk food addiction on health, the binominal logistic regression model was applied. Junk food addiction was the dependant variable. The variables which were significant in univariate logistic regression were included in the binary logistic regression model. It was found that obesity $[A O R=2.16(1.25,3.37)$, $p=0.005]$, habits $[A O R=2.36(1.41,3.94), p=0.001]$, use of smartphone/fitbit to monitor diet [AOR=2.04 $(1.15,3.65)$, $p=0.01]$ and use of smartphone/laptop/TV for recreational purposes for $>4$ hours $[A O R=3.1(1.53,6.26), p=0.001]$ were significantly associated with junk food addiction.

There was a weak positive correlation between BMI and addiction score [rho $=0.2, p<0.001]$ using Spearman's Rank correlation test as depicted in Figure 1. 


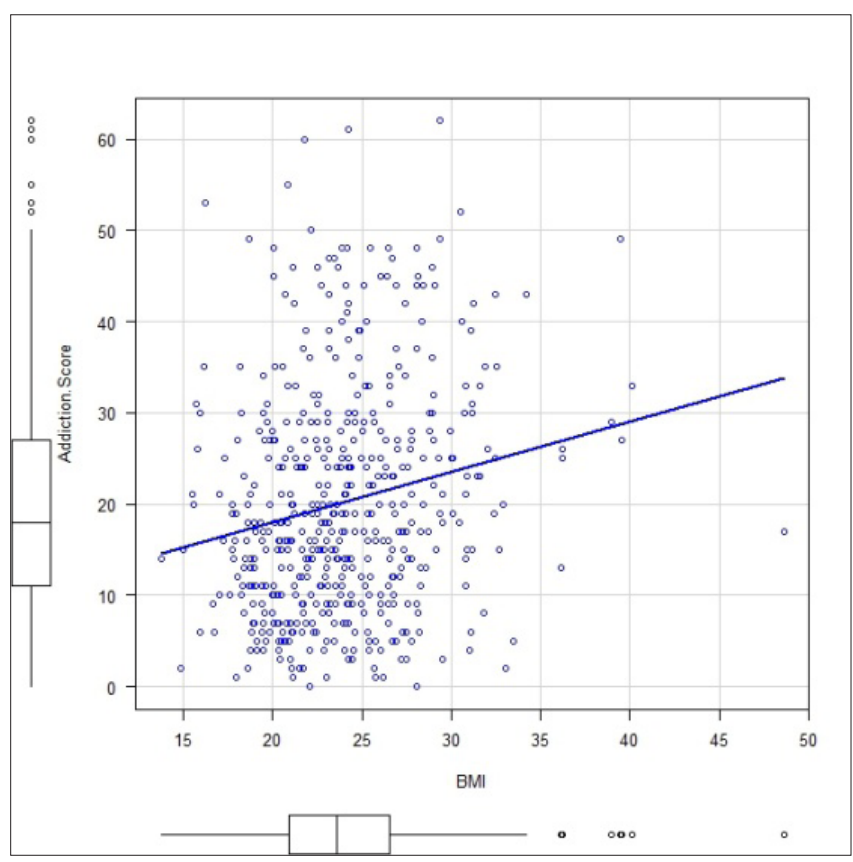

Figure I.Correlation between junk food addiction score and BMI

There was a significant difference in the proportion of addicts with acute illness $(z=3.52, p<0.001)$, chronic illness $(z=6.05, p<0.001)$ and habits $(z=3.85, p<0.001)$ compared to non-addicts.

There was a statistically significant difference in the median addiction scores among the subjects between the BMI categories by Kruskal-Wallis Rank Sum Test (chi squared=18.26, $p=0.001$ ). On further pair-wise comparison of $p$-values of BMI categories by Bonferroni test showed significant difference in the median junk food addiction score only between Normal and Obese Class II ( $p=0.002)$.

One hundred and thirty seven (27.4\%) was the overall prevalence of different diet fads followed for 3 months or more by the subjects. Table 3 describes the fad diets observed among the subjects.

One hundred and forty six (29.2\%) subjects had tried meal replacement items, $323(60.2 \%)$ nutraceuticals and 348 $(69.6 \%)$ novel food items anytime in the past 1 year. Only $9(6.2 \%)$ subjects had consumed meal replacement items, $37(11.5 \%)$ nutraceuticals and $30(8.6 \%)$ novel food items on a daily basis.

\section{Discussion}

Globalization of fast food has generated changes in societies and culture and forced people to consume fancy and high calorie fast foods, popularly known as junk foods. ${ }^{12}$ In the current study, we found that consumption of junk food is present across all generations, more so among the Millennials and Generation Z. Junk food addiction was mostly seen in the younger age group and majority had only mild addiction. Factors like obesity, habits (smoking, drinking), use of smartphones for recreational purposes and gadgets to monitor diet had independent effects on junk food addiction. The practice of fad diets, use of nutraceuticals and meal replacements were followed by many subjects.

The changing consumption pattern away from traditional food to processed and high-calorie food is gradually but significantly damaging human health leading to metabolic changes like obesity, high blood pressure and diabetes which are among the leading causes of death due noncommunicable diseases in India. ${ }^{12,13}$ The major health problems identified in the present study were diarrhoea and obesity which is understandable given the eating habits of the subjects.

Food is a known natural stimulus in the reward pathway. Junk food, given its hedonic properties may have a potential impact on the brain reward system through changes in the amygdala and hippocampus, similar to the same pathway observed for addiction to drugs and alcohol. ${ }^{14,15}$ Addiction consists of a number of distinct common components, that is, salience, mood modification, tolerance, withdrawal, conflict and relapse. ${ }^{16,17}$ The presence of these components is needed for diagnosis of addiction. The junk food industry targets youth because of the size of the market considering early initiation would keep them addicted throughout life. A perfect combination of salt, sugar, and fat with an intent to excite the brain, is used to boost the promotion and sale of junk food. ${ }^{18}$

Data published by the CDC, Atlanta observed that adults consuming fast food decreased with age similar to the present study and higher junk food consumption was among men than women in discordance to the present findings. ${ }^{19}$ In a study by Kaur M, the prevalence of junk food was high among all age groups and both the genders ${ }^{20}$

Table 3.Distribution of Subjects by Fad Diets Followed for 3 months or More $(n=500$ *

\begin{tabular}{|c|c|c|c|c|c|}
\hline S. No. & Diet & Female $(\mathbf{n = 2 8 8})$ & Male $(\mathbf{n = 2 1 2})$ & Total $(\mathbf{n = 5 0 0})$ & Z test, $\mathbf{p}$ value \\
\hline 1. & Atkins & $26(9.0)$ & $43(20.3)$ & $69(13.8)$ & $3.6,0.0003$ \\
\hline 2. & Keto & $25(8.7)$ & $34(16.0)$ & $59(11.8)$ & $2.52,0.011$ \\
\hline 3. & Zone & $42(14.6)$ & $48(22.6)$ & $90(18.0)$ & $2.31,0.02$ \\
\hline 4. & Veganism & $38(13.2)$ & $50(23.6)$ & $88(17.6)$ & $3.015,0.002$ \\
\hline
\end{tabular}

Figures in parenthesis indicate percentages; * Multiple response. 
In the present study, an attempt was made to measure junk food addiction through a novel scale and grade the addiction. There are hardly any studies on junk food addiction from India. The term "food addiction" is new and much research needs to be done. ${ }^{21}$ Junk food addiction was observed in about one fifth of the subjects. It was seen that majority had only mild addiction, an ideal stage for screening and intervention. Long-term health effects of junk food addiction need to be explored.

An online study conducted in USA reported $23 \%$ of children 5 to 12 years being classified as addicted to food, and a positive association with obesity. ${ }^{22}$ In a systematic review, the weighted mean prevalence of Yale food addiction diagnosis was $19.9 \%$ (5.4\%-56.8\%), more common among $>35$ years and females, different from the observations of the present study. ${ }^{23}$ In Australia, it was observed heavier TV and more frequent commercial TV viewing use was independently associated with higher-reported junk food consumption in concordance with the current findings. ${ }^{24}$

Millennials are becoming increasingly health-conscious and willing to pay a premium for good health. About $17 \%$ subjects used apps to monitor diet, and 35\% subjects used apps to monitor physical activity in the current study. Research shows that $36 \%$ of Indian millennials have a fitness app installed on their phones. About $45 \%$ think leading a healthy life is a priority. ${ }^{25}$

The obsession with the concept of ideal body encourages people to follow fad foods and diets overlooking the economic hardships, health hazards and questionable benefits to attain desired results. Alternate diet patterns were seen in one fourth of the subjects and mostly observed in males. Zone diet was popular in the current study. Malnutrition due to health fad diets may be an underestimated medical problem. Orthorexia nervosa, an alleged eating disorder is a pathological obsession with healthy food. ${ }^{26}$ The long-term potential deleterious effects of such high-fat diets have not been documented and remain a concern. ${ }^{27,28}$

\section{Conclusion}

Junk food addiction was observed in more than one tenth of the subjects. Majority had mild addiction and observed equally between Millennials and Generation Z. Diarrhoea was the most common acute health problems reported and overweight/obesity was most common chronic health problem reported. Obesity, habits and gadgets had independent effects on junk food addiction. More than one-forth subjects followed fad diets.

Larger studies using the novel junk food addiction scale covering wider geographic area and different sections of the society on changing dietary patterns across generations are needed for generalization of the study finding. Health education messages through mass media to inform on the harmful effects of junk food consumption and compulsory physical exercise in schools and colleges are need of the hour.

\section{Limitation}

Convenient sampling has its inherent bias of recruitment and the result obtained may not be the true picture. Generation X subjects were fewer in number and the lack of addiction in them may not be the true picture. The acute and chronic health issues reported are assumed to be due to consumption of junk food and not due to any other factors as informed by the subjects. The causal relation cannot be established for various factors measured and junk food addiction as they are beyond the scope of the study. Many other forms of diet such as the Mediterranean diet, Ornish diet and whole food diet form were not included in the study.

\section{Funding}

This research did not receive any specific grant from funding agencies in the public, commercial, or not-for-profit sectors.

\section{Conflict of Interest: None}

\section{Referrences}

1. Kaushik JS, Narang M, Parakh A. Fast Food Consumption In Children. Indian Pediatr 2011; 48(2): 97-101.

2. Keshari P, Mishra CP. Growing menace of fast food consumption in India: time to act. Int J Community Med Public Health 2016; 3(6): 1335-1362.

3. Raman R. The Zone Diet: A Complete Overview. [Internet] 2017April ${ }^{\text {th }}$ Available at: healthlinehttps:// www.healthline.com/nutrition/zone-diet\#section2 [last accessed on : $2^{\text {th }}$ Aug 2019].

4. Sa Vanna S, MS, RDN, LD. What's the Difference Between Keto and Atkins? [Internet] 2019 June 13 ${ }^{\text {th }}$. Available from: Healthlinehttps://www.healthline. com/nutrition/atkins-vs-keto\#atkins [Last accessed on: $10^{\text {th }}$ Aug 2019].

5. Times of India. Should you replace your meals with replacement shakes to lose weight? We tell you! [Internet] 2018 May $10^{\text {th }}$. Available from: https:// timesofindia.indiatimes.com/life-style/health-fitness/ weight-loss/should-you-replace-your-meals-withreplacement-shakes-to-lose-weight-we-tell-you/ articleshow/64111533.cms [Last accessed on: $5^{\text {th }}$ July 2019].

6. Christy Brissette. This is your body on fast food. The Washington Post. [Internet] 2018 March $1^{\text {st }}$ Available from: https://www.washingtonpost.com/lifestyle/ wellness/sneaking-a-little-junk-food-doesnt-meanall-is-lost/2018/02/26/828b75fa-1b36-11e8-9de1$147 d d 2 d f 3829$ story.html [Last accessed on: $17^{\text {th }}$ July 2019]. 
7. Michael Dimock. Defining generations: Where Millennials end and Generation Z begins. Pew Research Center.[Internet] 2019 Jan $17^{\text {th }}$ Available from: https:// www.pewresearch.org/fact-tank/2019/01/17/wheremillennials-end-and-generation-z-begins/ [Last accessed on: $13^{\text {th }}$ Aug 2019].

8. Sudarshan MK, Masthi NRR. Public Health Nutrition For Youth And Elderly. Practitioner's Guidance Series - VI. Karnataka Medical Council. 2017;74-102.

9. Meal Replacements. Amy Campbell. Diabetes self management.[Internet] 2017 Aug $4^{\text {th }}$ Available from: https://www.diabetesselfmanagement.com/ nutrition-exercise/weight-loss-management/mealreplacements/[Last accessed on $5^{\text {th }}$ Sep 2019].

10. R Studio Team (2016). R Studio: Integrated Development for R. RStudio, Inc., Boston, MA URL http://www. rstudio.com/.

11. World Health Organization. The Asia-Pacific Perspective: Redefining obesity and its treatment. The Lancet 2004; 363: 157-163.

12. Ashakiran, Deepthi R. Fast Food and their Impact on Health. JKIMSU 2012; 1: 7-15.

13. Pandey SK, Sharma V. World diabetes day 2018: Battling the Emerging Epidemic of Diabetic Retinopathy. Indian J Ophthalmol 2018; 66(11): 1652-1653. DOI: 10.4103/ ijo.IJO_1681_18.

14. Alonso-Alonso M, Woods SC, Pelchat $M$ et al. Food reward system: current perspectives and future research needs. Nutr Rev 2015; 73(5): 296-307. DOI: 10.1093/nutrit/nuv002.

15. Volkow ND, Wang GJ, Baler RD. Reward, dopamine and the control of food intake: implications for obesity. Trends Cogn Sci. 2011; 15(1): 37-46. DOI: 10.1016/j.tics.2010.11.001.

16. Blundell JE, Finlayson G. Is susceptibility to weight gain characterized by homeostatic or hedonic risk factors for overconsumption? PhysiolBehav 2004; 82(1): 21 25. DOI: 10.1016/j.physbeh.2004.04.021.[PubMed] [CrossRef] [Google Scholar].

17. Mark Griffiths. A 'components' model of addiction within a biopsychosocial framework. Journal of Substance Use 2005; 10(4): 191-197. DOI: 10.1080/ 14659890500114359.

18. Pachauri RK. The Pioneer.2016 JULY 1[Internet] Available from: https://www.dailypioneer.com/2016/ columnists/controlling-indias-junk-food-addiction. html[Last accessed on: $11^{\text {th }}$ Aug 2019].

19. Fryar CD, Hughes JP, Herrick KA, Ahluwalia N. Fast Food Consumption Among Adults in the United States, 2013-2016. NCHS Data Brief.No. 322.[Internet]October 2018 Available from: https://www.cdc.gov/nchs/data/ databriefs/db322-h.pdf [Last accessed on: $25^{\text {th }}$ Aug 2019].
20. Kaur M, M Hegde A. Are we Aware of what we are, we are what we Eat- An Epidemiological Survey. Int J ClinPediatr Dent 2008; 1(1): 13-16. DOI: 10.5005/jpjournals-10005-1003.

21. Ziauddeen $\mathrm{H}$, Fletcher PC. Is food addiction a valid and useful concept? Obes Rev 2013; 14(1): 19-28. DOI: 10.1111/j.1467-789X.2012.01046.x. [PMC free article] [PubMed] [CrossRef] [Google Scholar].

22. Burrows T, Skinner J, Joyner MA, Palmieri J, Vaughan K, Gearhardt AN. Food addiction in children: associations with obesity, parental food addiction and feeding practices. Eat Behav 2017; 26: 114-120. DOI: 10.1016/j. eatbeh.2017.02.004. [PubMed] [CrossRef] [Google Scholar].

23. Pursey KM , Stanwell P, Gearhardt AN, Collins CE, Burrows TL. The Prevalence of Food Addiction as Assessed by the Yale Food Addiction Scale: A Systematic Review. Nutrients 2014; 6: 4552-4590. DOI: 10.3390/ nu6104552.

24. Dixon HG, Scully ML, Wakefield MA, White VM, Crawford DA. The effects of television advertisements for junk food versus nutritious food on children's food attitudes and preferences. Soc Sci Med [Internet]. 2007; 65(7): 1311-1223. Available from: https://linkinghub. elsevier.com/retrieve/pii/S0277953607002730[Last accessed on: 2019 July 20].

25. Economic Times. What the millennial Indian wants: Not cars \& houses, just fun \& convenience. [Internet] 2017 Nov $2^{\text {nd }}$. Available from: //economictimes.indiatimes. com/articleshow/61452052.cms?from=mdr\&utm source=contentofinterest\&utm_medium=text\&utm_ campaign=cppst [Last accessed on: $17^{\text {th }}$ Aug 2019].

26. Nauta K, Toxopeus K, Eekhoff EMW. [Malnutrition due to an extremely "healthy" diet; a new eating disorder?]. Ned Tijdschr Geneeskd [Internet] 2016; 160: A9164. Available from: http://www.ncbi.nlm.nih.gov/ pubmed/27299484[Last accessed on: $17^{\text {th }}$ Aug 2019].

27. McAuley KA, Hopkins CM, Smith KJ et al. Comparison of high-fat and high-protein diets with a high-carbohydrate diet in insulin-resistant obese women. Diabetologia 2005; 48: 8. https://doi.org/10.1007/s00125-0041603-4.

28. Leung $B$, Lauche $R$, Leach $M$, Zhang $Y$, Cramer $H$, Sibbritt D. Special diets in modern America: Analysis of the 2012 National Health Interview Survey data. Nutrition and Health 2018; 24(1): 11-18. https://doi. org/10.1177/0260106017732719. 